\title{
A FAMILIAL CASE REPORT OF A 13;22 CHROMOSOMAL TRANSLOCATION WITH RECURRENT INTRACYTOPLASMIC SPERM INJECTION FAILURE
}

\author{
Verma $\mathrm{S}^{1}$, Shah $\mathrm{R}^{1}$, Bhat $\mathrm{A}^{1}$, Bhat $\mathrm{GR}^{1}$, Dada $\mathrm{R}^{2}$, Kumar $\mathrm{R}^{1, *}$ \\ *Corresponding Author: Dr. Rakesh Kumar, Assistant Professor, Coordinator, Genetics Research Group, \\ Department of Biotechnology, Shri Mata Vaishno Devi University, Katra, Jammu \& Kashmir, 182320, \\ India. Tel.: +91-91-285-695; ext. 2288. Mobile: +91-94-419-279-629. Fax: +91-91-285-694. \\ E-mail: kumar.rakesh@,smvdu.ac.in
}

\begin{abstract}
The importance of cytogenetic analysis in a family with reproductive failure in two siblings is highlighted, where two siblings and their mother presented with a balanced translocation between chromosomes 13;22. The clinical evaluation had shown the female to be normal and the male to be oligoasthenoteratozoospermic despite repeated semen analysis. The couple was referred to our laboratory after three consecutive intracytoplasmic sperm injection (ICSI) failures at a local assisted reproductive technique (ART) center. Peripheral blood lymphocytes, obtained for karyotyping, were studied by a standard Gbanding technique. Chromosomal analysis of the members of the pedigree, including the probands, showed the presence of the same translocation, $\mathrm{t}(13 ; 22)(\mathrm{q} 21.2 ; \mathrm{q} 13.3)$, carried by three generations of the family. The sister and the mother of the proband had multiple spontaneous abortions in the first trimester. The spouses, when examined cytogenetically, were found to be normal. We propose the involvement of a balanced $\mathrm{t}(13 ; 22)(\mathrm{q} 21.2 ; \mathrm{q} 13.3)$ chromosomal translocation in the pathogenesis of recurrent ART or spontaneous reproductive failures. Hence, it is suggested that all cases with structural chromosomal abnormalities be counseled prior to opting for ART and undergoing pre-implantation genetic diagnosis (PGD). This would
\end{abstract}

\footnotetext{
${ }^{1}$ Department of Biotechnology, Shri Mata Vaishno Devi University (SMVDU), Katra, Jammu \& Kashmir, India;

${ }^{2}$ Laboratory for Molecular Reproduction and Genetics, Anatomy Department, All India Institute of Medical Science (AIIMS), New Delhi, India
}

prevent recurrent financial, physical and emotional stress in couples seeking ART.

Keywords: Assisted reproductive technique (ART) center; Infertility; Intracytoplasmic sperm injection (ICSI); In vitro fertilization (IVF); Karyotyping; Translocation, Preimplantation genetic diagnosis (PGD); Spontaneous abortions.

\section{INTRODUCTION}

Reproductive failure is the inability to achieve conception or sustain a pregnancy to term. It is estimated that fetal viability is only achieved in $30.0 \%$ of all human conceptions [1]. Chromosomal abnormalities are a known contributory factor in infertility, bad obstetric history $(\mathrm{BOH})$ and spermatogenetic arrest. Male infertility may be associated with chromosomal abnormalities, involving sex chromosomes (4.0-8.0\%) and autosomes (1.0-2.0\%) [2]. Complete spermatogenic and partial spermatogenetic arrest is mainly associated with sex chromosomal aneuploidies and autosomal structural abnormalities, respectively [3]. The frequency of autosomal reciprocal translocations is estimated to be $0.25 \%$ in the general population, $0.5 \%$ in azoospermia and $0.7 \%$ in oligozoospermia [4,5]. The incidence of these genetic abnormalities increases with decline in semen quality [6]. Kumar et al. [7] showed that Robertsonian translocations $\mathrm{t}(13 ; 14)$ and $\mathrm{t}(13 ; 13)$ are associated with extremely poor semen quality (low sperm count and abnormal sperm morphology). Guichaoua et al. [8] reported a sterile male with 14:22 Robertsonian translocation, who was oliogoasthenozoospermic with normal sperm morphology. Reciprocal translocation carriers are phenotypically normal but with poor semen quality [9] 
and their severity depends on whether they are balanced or unbalanced. Unbalanced reciprocal translocations cause severe effects ranging from low IQ, mental retardation, physical and skeletal defects [10]. Balanced translocations show variable sperm parameters, ranging from normal sperm count to oligospermia or azoospermia [4]. Even in patients with a normal sperm count, reciprocal translocation carriers are at a higher risk of pre and post implantation losses or abnormal pregnancy outcomes. Chromosomal translocations are known to result in poor quality of blastocyst and implantation failure. Assisted reproductive technique (ART) intracytoplasmic sperm injection (ICSI) has proved to be a boon to men with poor semen quality [11], but in developing countries such as India, the cost of recurrent ART failures take a toll on patients' financial and emotional well being. Couples having a history of spontaneous abortions should undergo genetic analysis and counselling before planning ART, particularly ICSI, where critical natural steps are bypassed.

\section{CASE REPORT}

Family Case Report. The couple was not consanguineous and primarily infertile, involving a 31-year-old healthy male (II-3) and his 27-year-old wife (II-4) (Figure 1). They visited our laboratory after failing ICSI three times. On recording the detailed family history of the proband (II-3), his sister (II-2) and mother (I-2), they were found to have a $\mathrm{BOH}$. Affected members of the family along with their spouses were called in for cytogenetic

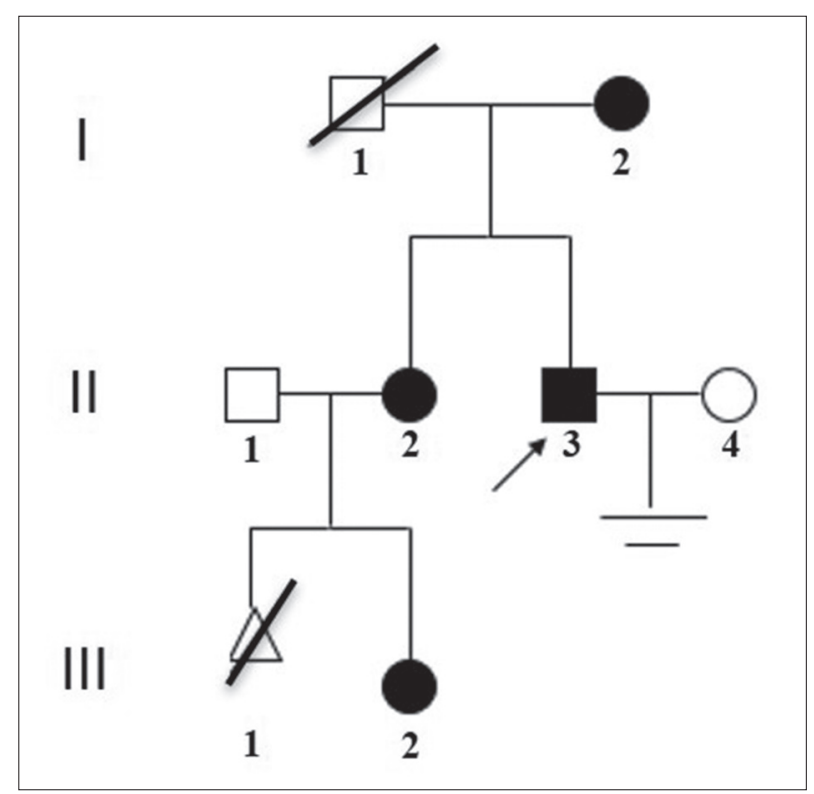

Figure 1. Pedigree of the studied family. investigation (father of the proband was deceased). A detailed family, medical and reproductive history was taken in each case and the pedigree drawn. Occurrence of other factors, such as congenital malformations, drug addictions, radiation exposure or toxic environmental agents, was ruled out. Routine clinical investigations also ruled out any infectious or autoimmune cause for infertility.

The proband was a healthy male $(178 \mathrm{~cm} / 76 \mathrm{~kg})$ with well developed secondary sexual characters. He was oligoasthenoteratozoospermic ( $95000 \mathrm{spermatozoa} / \mathrm{mL}$ ). Endocrine evaluation showed that follicle-stimulating hormone (FSH) (6.5 mIU/mL), luteinizing hormone (LH) $(4.3 \mathrm{mIU} /$ $\mathrm{mL})$ and testosterone $(360 \mathrm{ng} / \mathrm{dL})$ were normal. Because of the spermiogram results and the duration of infertility, ICSI was performed and failed three times. The wife of the proband was normal on gynecological examination.

The proband's sister (II-2), aged 26 years $(158 \mathrm{~cm} / 56$ $\mathrm{kg}$ ), suffered three first trimester spontaneous abortions. Her husband was clinically and cytogenetically normal. Her hormonal profile (FSH $5.5 \mathrm{mIU} / \mathrm{mL}$, LH $15.0 \mathrm{mIU} /$ $\mathrm{mL}$ and prolactin (PRL) $11.0 \mathrm{ng} / \mathrm{dL}$ ) was within the normal range.

The mother (I-2) of the proband was 66 years old $(155 \mathrm{~cm} / 69 \mathrm{~kg})$. Her two children were conceived after 12 years of marriage; and she had a history of repeated miscarriages in the first trimester of pregnancy, but was not able to recollect her case history properly.

Ethical clearance was obtained prior to the study from the Ethics Clearance Committee of the All India Institute of Medical Sciences (AIIMS), New Dehli, India. The patients were referred from the infertility clinic of the Department of Urology, AIIMS, and the ART Centre of the Army Research and Referral Hospital, New Delhi, India. The study was explained to both patients and controls in English and Hindi (local language).

\section{METHODOLOGY}

Semen Analysis [1]. Semen samples of the proband and his brother-in-law were collected by masturbation after minimum of 48 hours and not longer than 7 days of sexual abstinence; and analyzed according to WHO guidelines.

Chromosome Preparation [12]. Chromosomal analysis was performed on lymphocyte cultures and chromosomes analyzed by G-banding [13]. Metaphases were analyzed using Cytovision Software DM2500 (Leica Biosystems Lab Solutions, Wetzlar, Hesse, Germany) and classified according to the International System for Human Cytogenetic Nomenclature (ISCN 2016) [14]. At least 120-150 metaphases were analyzed in each case. 


\section{RESULTS}

The proband was oligoasthenoteratozoospermic. His average sperm count was 0.95 million $/ \mathrm{mL}$ after three semen analyses. The grade A, B, C and D motility was $38.0,30.0,20.0$ and $12.0 \%$, respectively. The abnormal morphology was found in $79.0 \%$ sperms $(65.0 \%$ sperms had coiled tails, $14.0 \%$ had tapered heads and $21.0 \%$ had normal morphology). The proband was found to carry a balanced translocation between chromosomes 13;22. The breakpoint was at 13q21.2 and the terminal part was transferred to 22q13.3. The karyotype was 46;XY,t(13;22) (q21.2; 13.3 ). Incidentally, the same translocation was observed in the mother and sister of the proband. The karyotypes of mother and sister were $46, \mathrm{XX}, \mathrm{t}(13 ; 22)$ (q21.2;q13.3) and 46,XX,t(13;22)(q21.2;q13.3), respectively. The sister of the proband got pregnant during the investigation and was counseled about the risk to the fetus, of inheriting the genetic abnormality. The couple opted for amniocentesis (in a private center other than AIIMS, New Delhi, India). The amniocentesis was done at the 17 th week of pregnancy and the fetus was found to carry the same translocation $(46 ; \mathrm{XX}, \mathrm{t}(13 ; 22)(\mathrm{q} 21.2 ; \mathrm{q} 13.3)$ as that of the mother (shown in Figure 2). However, couple decided to continue the pregnancy. The growth of the fetus was monitored through ultrasound and mother (II-2) delivered a phenotypically normal girl.

\section{DISCUSSION}

Spontaneous abortion involves pregnancy fatalities from the start until the 24th week of pregnancy $[15,16]$.
Many risk factors are related with early pregnancy loss, including genetic and endocrine irregularities, immune dysfunction and progressive maternal age [17]. Reciprocal translocations are the leading cause of recurrent miscarriages [18]. Translocation of $13 ; 22$ is a leading cause of partial trisomy with elevated levels of neutrophils in patients [19].

We describe here a familial case of $t(13: 22)$ in three generations of a family with a $\mathrm{BOH}$. Family members were phenotypically normal because of nature of the translocation. Pedigree analysis helped in tracking the path of transmission of the translocation from mother (I-2). From the proband's sister (II-2), the translocation transmitted to her child (III-2). We were successful in identifying the breakpoint interval on the long arm of chromosome 13q21. It has been reported to be an AT-rich repeat region and very prone to rearrangements due to the presence of fragile sites. The sequences and mechanisms responsible for the fragility at these sites remains largely unknown [20,21]. Deletions in chromosome 13q21 occur frequently in head and neck squamous cell carcinoma (HNSCC) [22]. Manjunatha et al. [23] studied five mentally retarded patients having fragile sites on chromosome $13 \mathrm{q} 21$. Though the breakpoint interval is the same, no family member in the present study had mental retardation or HNSCC. The infertility in men with autosomal aberrations may be due to the physical contact of unpaired autosomal material with sex chromosomes, which adversely affects meiotic segregation and may lead to spermatogenic arrest [24,25]. Such a reciprocal translocation leads to meiotic segregational abnormalities. The patterns of inheritance are complex and depend on the chromosomes involved and the size of

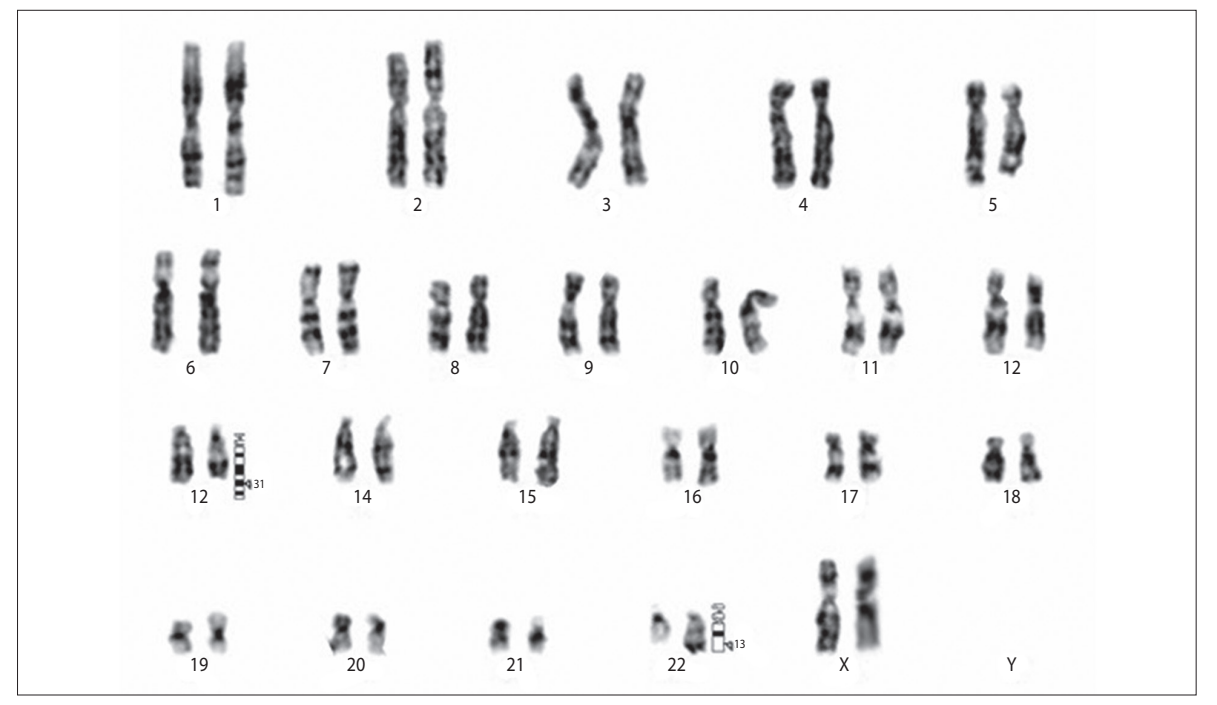

Figure 2. G-banded karyotype showing the 46,XX,t(13;22)(q21.2;q13.3) chromosomal complement. 
the rearrangements [26-28]. Meiotic studies have shown that translocations may result in spermatogenetic arrest or impairment. However, our findings were in contradiction to the report by Matsuda et al. [29] that close relatives of the affected person carrying same translocation will be fertile. The present study has proved it beyond doubt that translocations could cause recurrent reproductive loss, even though carriers are phenotypically normal. Recent advancement in the field of infertility has led to strong argument of genetic analysis pre or post implantation.

Poor fertilization and pregnancy rate has been reported in several studies on translocation carriers opting for ART [30]. Preimplantation genetic diagnosis (PGD) in such cases has shown a very high incidence of aneuploidies, and structural abnormalities [31,32]. This study is highly significant in this era of ART, where the majority of couples with $\mathrm{BOH}$ or infertility opt for ART/ICSI. The ART is a very expensive technique and is usually not covered by medical insurance, and if it fails recurrently, leads to severe physical and financial stress. Despite major advances in ART and professional expertise, the carry home live birth rate following ART is $25.0-35.0 \%$. It has been reported that genetic abnormality could be a major cause for fertilization failure or poor blastocyst development following ART and may lead to pre or post implantation failure $[8,33]$.

Thus, all couples with $\mathrm{BOH} /$ reproductive and recurrent ART failure should undergo genetic analysis and those results could be corerelated with PGD of the blastocysts that are expected to be transferred. On conception, the patient should be followed by prenatal diagnosis. The present study is one of the finest case report of familial $\mathrm{BOH}$, recurrent ART failures and chromosomal abnormality.

\section{ACKNOWLEDGMENTS}

The authors thank Professor (Retired) R.N.K. Bamezai (Coordinator National Centre of Applied Human Genetics, School of Life Sciences, Jawaharlal Nehru University, New Delhi, India) for critical evaluation of the article, and Ms. Sudeeksha Raina, freelance editor for English language and formatting. R. Kumar and R. Dada primarily planned and performed the study. S. Verma and R. Shah edited the manuscript. A. Bhat and G.R. Bhat made technical suggestions on the manuscript.

Declaration of Interest. The authors report no conflicts of interest. The authors alone are responsible for the content and writing of this article.

Funding. Partial funding for this study was sanctioned by SERB-DST Government of India: YSS/2014/000659 [financial assistance to S. Verma (Fellowship)] and DST, Government of India (DST/SSTP/J\&K/459) (Leica DM2500).

\section{REFERENCES}

1. Wang J, Sauer MV. In vitro fertilization (IVF): A review of 3 decades of clinical innovation and technological advancement. Ther Clin Risk Manag. 2006; 2(4): 355-364.

2. Gekas J, Thepot F, Turleau C, Siffroi JP, Dadoune JP, Briault S, et al. Chromosomal factors of infertility in candidate couples for ICSI: An equal risk of constitutional aberrations in women and men. Hum Reprod. 2001; 16(1): 82-90.

3. Heard E, Turner J. Function of the sex chromosomes in mammalian fertility. Cold Spring Harbor Perspect Biol. 2011; 3(10): a002675.

4. Zhang H, Wang R, Li L, Sun W, Zhang H, Liu R. Male carriers of balanced reciprocal translocations in Northeast China: Sperm count, reproductive performance, and genetic counseling. Genet Mol Res. 2015; 14(4): 18792-18798.

5. Mau-Holzmann U. Somatic chromosomal abnormalities in infertile men and women. Cytogenet Genome Res. 2005; 111 (3-4): 317-336.

6. Elfateh F, Wang R, Zhang Z, Jiang Y, Chen S, Liu R. Influence of genetic abnormalities on semen quality and male fertility: A four-year prospective study. Iran J Reprod Med. 2014; 12(2): 95-102.

7. Kumar R, Tanwar M, Ammini AC, Kumar R, Gupta NP, Sharma RK, et al. Robertsonian translocation and their role in pathogenesis of recurrent in vitro fertilization failure. Med Sci Monit. 2008; 14(12): CR617-CR620.

8. Guichaoua M, Quack B, Speed R, Noel B, Chandley A, Luciani J. Infertility in human males with autosomal translocations: Meiotic study of a 14;22 Robertsonian translocation. Hum Genet. 1990; 86(2): 162-166.

9. Suganya J, Kujur SB, Selvaraj K, Suruli MS, Haripriya G, Samuel CR. Chromosomal abnormalities in infertile men from southern India. J Clin Diagn Res. 2015; 9(7): GC05-GC10.

10. Vasilevska M, Ivanovska E, Kubelka Sabit K, Sukarova-Angelovska E, Dimeska G. The incidence and type of chromosomal translocations from prenatal diagnosis of 3800 patients in the Republic of Macedonia. Balkan J Med Genet. 2013; 16(2): 23-28. 
11. Chatziparasidou A, Christoforidis N, Samolada G, Nijs M. Sperm aneuploidy in infertile male patients: A systematic review of the literature. Andrologia. 2015; 47(8): 847-860.

12. Rooney DE, Czepulkowski BH, Editors. Human Cytogenetics: A Practical Approach. Volume II: Malignancy and Acquired Abnormalities, 2nd ed. Oxford, Oxfordshire, UK: Oxford University Press, 2009.

13. Sumner A. The nature and mechanisms of chromosome banding. Cancer Genet Cytogenet. 1982; 6(1): 59-87.

14. McGowan-Jordan J, Simons A, Schmid M, Editors. An International System of Human Cytogenomic Nomenclature (2016). Basel, Switzerland: S. Karger AG, 2016.

15. Murphy F, Merrell J. Negotiating the transition: Caring for women through the experience of early miscarriage. J Clin Nurs. 2009; 18(11): 1583-15891.

16. Shamsi MB, Venkatesh S, Pathak D, Deka D, Dada R. Sperm DNA damage and oxidative stress in recurrent spontaneous abortion (RSA). Indian J Med Res. 2011; 133(5): 550-551.

17. Zarifian A, Farhoodi Z, Amel R, Mirzaee S, Hassanzadeh-Nazarabadi M. Balanced chromosomal rearrangement in recurrent spontaneous abortions: A case report. Int J Mol Cell Med. 2012; 1(4): 225-228.

18. Carp H, Guetta E, Dorf H, Soriano D, Barkai G, Schiff E. Embryonic karyotype in recurrent miscarriage with parental karyotypic aberrations. Fertil Steril. 2006; 85(2): 446-450.

19. Moedjono SJ, Sparkes RS. Partial trisomy of 13 (pter to $\mathrm{q} 12)$ due to $47, \mathrm{XY},+\operatorname{der}(13), \mathrm{t}(13 ; 22)(\mathrm{q} 12 ; \mathrm{q} 13)$ mat. Hum Genet. 1979; 50(3): 241-246.

20. Kato T, Kurahashi H, Emanuel BS. Chromosomal translocations and palindromic AT-rich repeats. Curr Opin Genet Dev. 2012; 22(3): 221-228.

21. Edelmann L, Spiteri E, Koren K, Pulijaal V, Bialer $\mathrm{M}$, Shanske A, et al. AT-rich palindromes mediate the constitutional $\mathrm{t}(11 ; 22)$ translocation. Am J Hum Genet. 2001; 68(1): 1-13.

22. Golam Sabbir M, Roy A, Mandal S, Dam A, Roychoudhury S, Panda CK. Deletion mapping of chromosome $13 q$ in head and neck squamous cell carcinoma in Indian patients: Correlation with prognosis of the tumour. Int J Exp Pathol. 2006; 87(2): 151-161.
23. Manjunatha K, Chetan G, Arathi R, Rao GB, Latha $\mathrm{P}$, Padma S, et al. Frequency, association and genetic implications of chromosomal fragile sites in mental retardation. Int J Hum Genet. 2002; 2(1): 33-39.

24. Shamsi M, Kumar K, Dada R. Genetic and epigenetic factors: Role in male infertility. Indian J Urol. 2011; 27(1): 110-120.

25. Gardner RJM, Sutherland GR, Shaffer LG, Editors. Chromosome Abnormalities and Genetic Counseling, 4th ed. New York, NY, USA: Oxford University Press, 2012.

26. Harton GL, Tempest HG. Chromosomal disorders and male infertility. Asian J Androl. 2012; 14(1): 32-39.

27. Daniel A. Spontaneous loss of fetuses with chromosomally unbalanced D/21 - or reciprocal translocations in late pregnancy. Am J Med Genet Part A. 1989; 33(2): 285

28. Midro AT, Stengel Rutkowski S, Stene J. Experiences with risk estimates for carriers of chromosomal reciprocal translocations. Clin Genet. 1992; 41(3): 113-122.

29. Matsuda T, Nonomura M, Okada K, Hayashi K, Yoshida O. Cytogenetic survey of subfertile males in Japan. Urol Int. 1989; 44(4): 194-197.

30. Evgeni E, Charalabopoulos K, Asimakopoulos B. Human sperm DNA fragmentation and its correlation with conventional semen parameters. J Reprod Infertil. 2014; 15(1): 2-14.

31. Munné S. Preimplantation genetic diagnosis for aneuploidy and translocations using array comparative genomic hybridization. Curr Genomics. 2012; 13(6): 463-470.

32. Coulam C, Jeyendran R, Fiddler M, Pergament E. Discordance among blastomeres renders preimplantation genetic diagnosis for aneuploidy ineffective. J Assist Reprod Genet. 2007; 24(1): 37-41.

33. Timeva T, Shterev A, Kyurkchiev S. Recurrent implantation failure: The role of the endometrium. J Reprod Infertil. 2014; 15(4): 173-183. 